\title{
Effect of Furin inhibitor on lung adenocarcinoma cell growth and metastasis
}

\author{
Yong-Chao Ma ${ }^{\dagger}$, Wen-Juan Fan ${ }^{\dagger}$, Shu-Mei Rao, Li Gao, Zhan-Yu Bei and Song-Tao Xu
}

\begin{abstract}
Background: To investigate the mechanisms of lung adenocarcinoma cell metastasis and provide a theoretical basis for the in-depth study of lung adenocarcinoma.

Methods: A549 cells are incubated with different concentrations of Furin inhibitor for indicated times. The proliferation and migration were confirmed with MTT, colony formation, wound Healing and Transwell assayes. Hochest 33342 / PI double staining was used to detect apoptosis. Cell migration and apoptosis associated proteins were analysed by enzyme-linked immunosorbent assay (ELISA) and western blot.

Results: We have found that Furin inhibitor play a significant role in inhibition A549 cell growth. And we also found cell migration was inhibited significantly upon Furin inhibitor treatment.

Conclusion: The proliferration and migration of A549 cell were inhibited by Furin inbitor through down-regulation the expression of migration and apoptosis related proteins.
\end{abstract}

Keywords: Fruin inhibitors, Lung adenocarcinoma, Apoptosis, Migration

\section{Background}

Lung cancer is one of the most serious threats to human health in the world, and the incidence is increasing year by year [1]. It was estimated that the number of the patients dying from lung cancer was larger than the total number of patients dying from prostate cancer and colorectal cancer one year [2]. Metastasis and recurrence is the leading cause of death in patients with lung cancer, about $90 \%$ of the lung cancer patients died from tumor metastasis [3]. Thus depth study on the molecular mechanism of lung cancer invasion and metastasis is necessary.

Furin is an important member of the family of proprotein processing enzyme and highly expressed in a variety of tumors [4-6]. Many proteins which are closely related to tumor development, including Notch, Wnt, MT1-MMP, VEGF, etc., must be cut by Furin [4,7]. So, Furin expression can be used as the marker of tumor progression or as prognostic indicators [8,9]. Mbikay, etc. [10] studies have shown that Furin is highly expressed in lung cancer, and is closely related to lung cancer development. In our present study, we apply Furin inhibitor

\footnotetext{
* Correspondence: xusongtao-008@163.com

${ }^{\dagger}$ Equal contributors

Luo He Medical Colledge, Daxue Road, \#148, Luohe City, Henan Province 462002, P.R. China
}

a1-PDX to detect the effect on the migration and invasion of A549 cells.

\section{Materials and methods}

Human lung adenocarcinoma cell line A549 was purchased from Chinese Academy of Medical Sciences Peking Union cell libraries, cultured in RPMI1640 medium (Gibco, USA) contained with $10 \%$ fetal bovine (FBS), 100 units $/ \mathrm{mL}$ penicillin and $100 \mu \mathrm{g} / \mathrm{mL}$ streptomycin at $37^{\circ} \mathrm{C}, 5 \% \mathrm{CO}_{2}$ and humidity.

Furin inhibitor a1-PDX (Merck No.126850-2.5 MG) was dissolved in DMSO. Rabbit anti-human VEGF-C, VEGF-D, MT1-MMP, Caspase-3, Caspase-9, Bcl-2 and GAPDH antibodies were purchased from Santa Cruz Biotechnology (Santa Cruz, USA). Anti-rabbit IgG-HRP were purchased from Sigma (Sigma, USA); MTT, Hochest 33342, Transwell kit were purchased from Promega Corporation; MMP2, MMP9 ELISA kits were purchased from Nanjing Jiancheng Biological Reagent Company. Other reagents were of analytical grade.

\section{Cell proliferation studies by MTT assay}

A549 cells in logarithmic growth phase were seeded in 96well plate $\left(5 \times 10^{3}\right.$ per well) for $24 \mathrm{~h}$. Various concentrations

\section{Biomed Central}

(c) 2014 Ma et al.; licensee BioMed Central Ltd. This is an Open Access article distributed under the terms of the Creative Commons Attribution License (http://creativecommons.org/licenses/by/2.0), which permits unrestricted use, distribution, and reproduction in any medium, provided the original work is properly credited. The Creative Commons Public Domain Dedication waiver (http://creativecommons.org/publicdomain/zero/1.0/) applies to the data made available in this article, unless otherwise stated. 

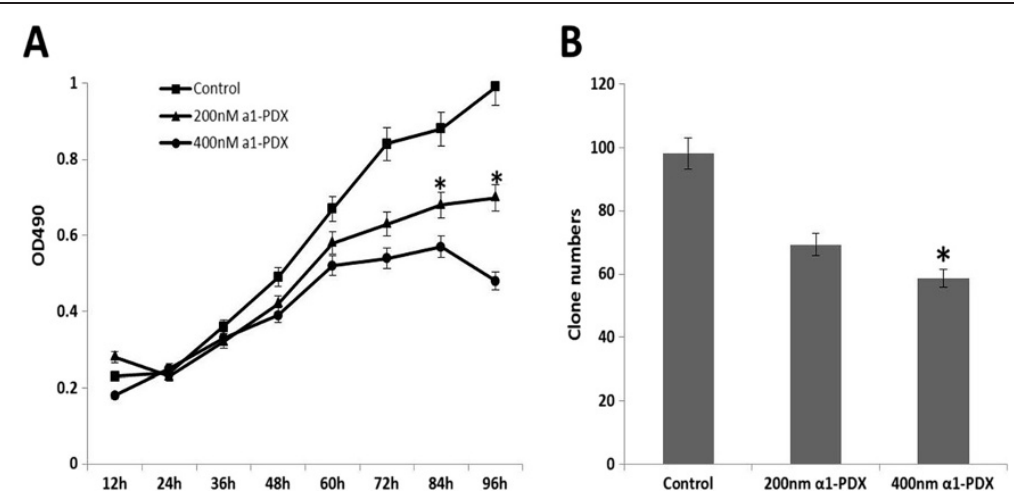

Figure 1 Effect of a1-PDX on the proliferation of A549 cell. A549 cells were treated with a1-PDX for indicated times, the proliferation was detected with MTT assay (A). Individual cell was seeded on the 6-well plate, followed with colony analysis (B). Data are expressed as overall Mean \pm SE from three independent experiments. ( ${ }^{*} P<0.05$, vs control).

of a1-PDX (200 nM, $400 \mathrm{nM}$ ) were added, then cultured for $24 \mathrm{~h} \sim 96 \mathrm{~h}$. MTT reagent $(5 \mathrm{mg} / \mathrm{mL})$ was added to each well and incubated for $4 \mathrm{~h}$ at $37^{\circ} \mathrm{C}$. The formazan crystals were solubilized by the addition of $150 \mu \mathrm{L}$ DMSO to each well. The optical density at $490 \mathrm{~nm}$ was measured and cell viability was determined by the growth curve.

\section{Colony formation ability of A549 cell}

Monolayer cultured cells were pipetted into individual cells, then suspended in 10\% FBS-containing RPMI 1640 medium, after that we inoculated these cells in petri dishes. Different concentrations of a1-PDX (200 nM, $400 \mathrm{nM})$ were added and incubated for 2 weeks. Then immobilized and stained for $10 \mathrm{~min}$ by Giemsa dye. After washing and air drying, clone numbers were directly counted and analyzed.

Hochest 33342 / PI staining for apoptosis analysis A549 cells were treated by different concentrations of a1-PDX for $48 \mathrm{~h}$ and washed twice with cold PBS, then incubated with $5 \mu \mathrm{L}$ DAPI /PI staining buffer for $15 \mathrm{~min}$
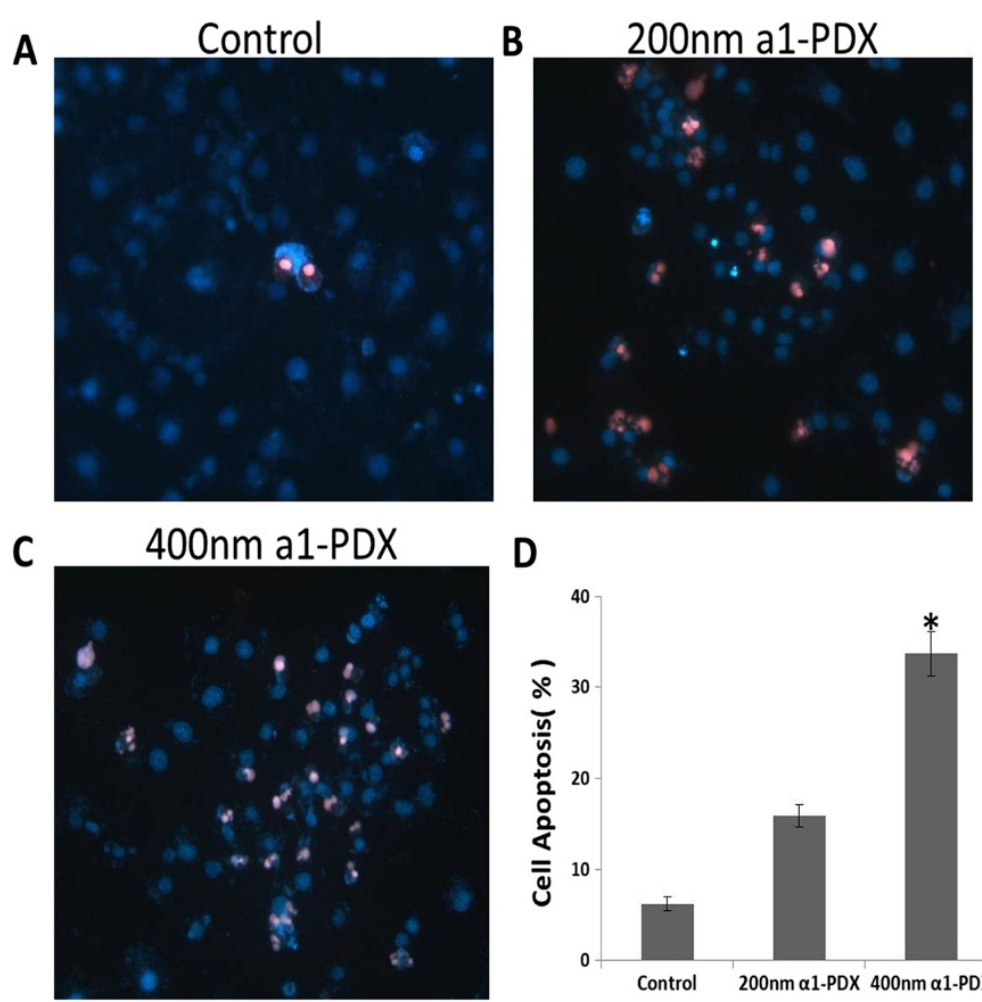

D

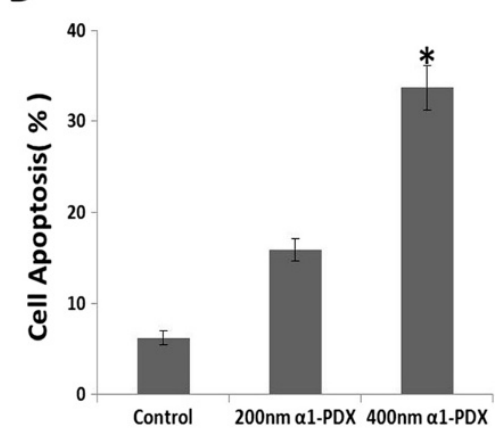

Figure 2 A1-PDX induce apoptosis in A549 cells. Cell apoptosis was determined by Hoechst/PI double staining (A, B, C, D). Data are expressed as Mean $\pm \mathrm{SE}$ from three independent experiments. ( ${ }^{*} P<0.05$ vs control). 

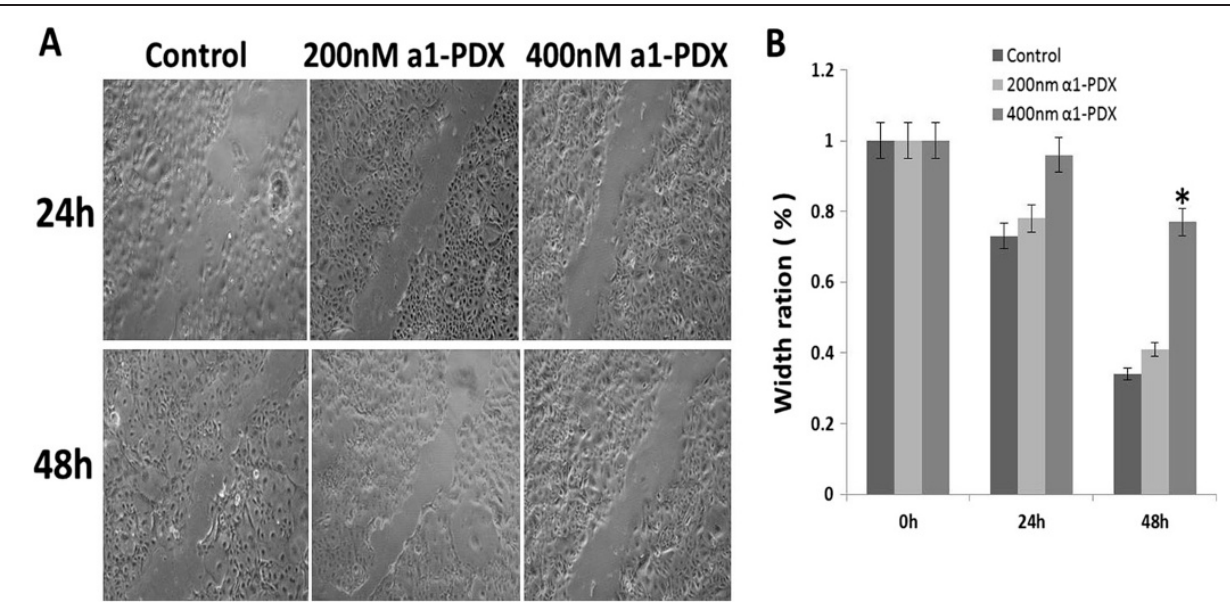

Figure 3 Effect of a1-PDX on the cell migration by wound healing assay. Monolayer A549 cell grew to 100\% confluent and wounded by a sterile $200 \mu \mathrm{l}$ pipette tip, the ability of cell migration was monitored with an inverted microscopy equipped with a digital camera (A). Statistical analysis of three independent experiments (B) $(* P<0.05$ vs control).

at $25^{\circ} \mathrm{C}$ in the dark. The percentage of cells undergoing apoptosis was determined.

\section{Monolayer cell wound healing assay}

The $100 \%$ confluent monolayer cells were scraped with sterile $200 \mu \mathrm{L}$ pipette tip and cell debris was washed with PBS. The cells migrated into the wounded areas and these process were photographed at the indicated times with an inverted microscopy equipped with a digital camera. The extent of healing was defined as the ratio of the difference between the original and the remaining wound areas compared with the original wound area.
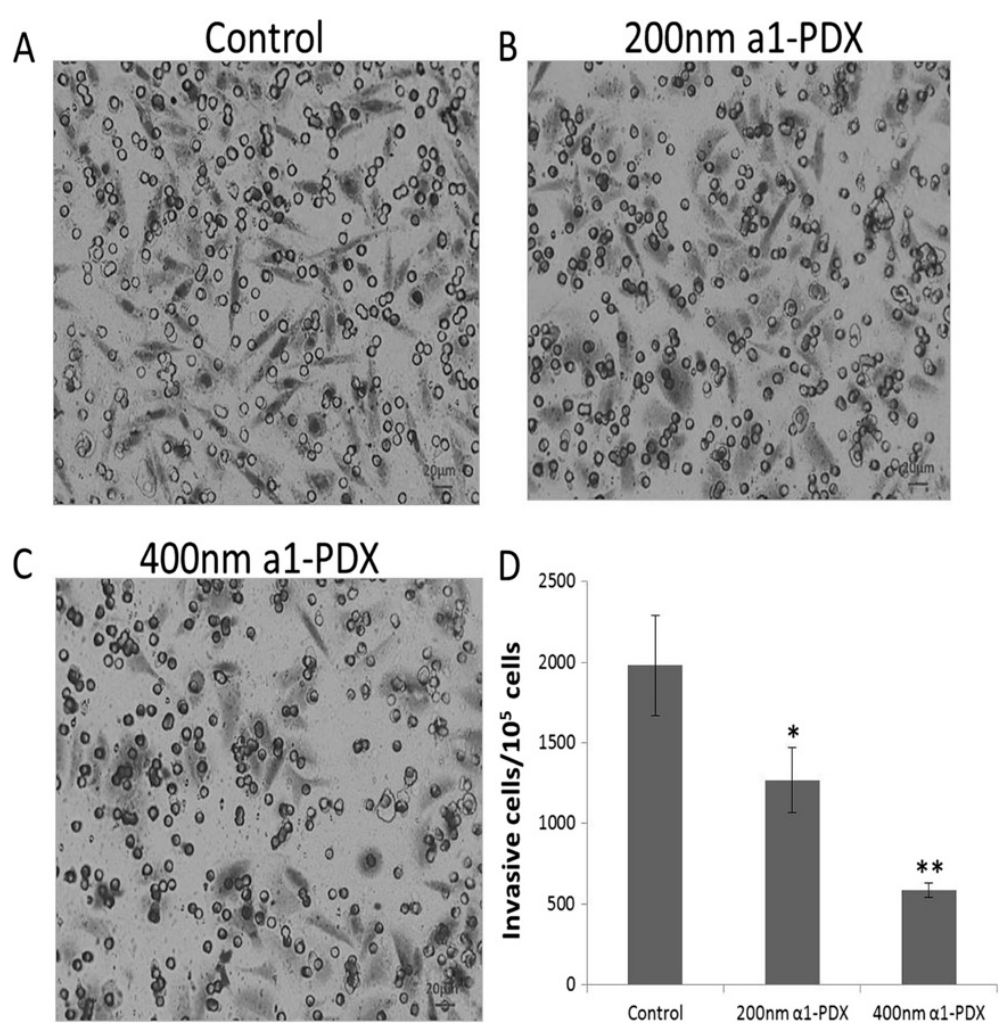

Figure 4 A549 cell invasion ability upon a1-PDX treatment. The invasion cells were detected by Transwell assay (A, B, C) and counted for statistical analysis (D) ${ }^{*} P<0.05,{ }^{* *} P<0.01$ vs control). 


\section{Transwell invasion assay}

A549 cells $\left(1 \times 10^{5}\right)$ were incubated with different concentrations of a1-PDX on the upper chamber of the transwell, containing $200 \mu \mathrm{L}$ of RPMI1640 medium without $10 \%$ FBS. Transwell lower chamber is filled with $500 \mu \mathrm{L}$ of complete RPMI1640 medium containing 10\% FBS. The cells were allowed to migrate for $48 \mathrm{~h}$, then fixed and stained with $0.1 \%$ crystal violet for $10 \mathrm{~min}$. The migrated clones were photographed under an optical microscope. The cell numbers were counted at 12 different areas.

\section{Western blot analysis}

A549 cells were treated and collected as described above. Cells were lysed in RIPA buffer (50 mM Tris (pH 7.4), $150 \mathrm{mM} \mathrm{NaCl}, 1 \%$ Triton X-100, 0.1\% SDS, $1 \%$ sodium deoxycholate, $5 \mathrm{mM}$ EDTA, $100 \mathrm{mM} \mathrm{NaF}$, and $1 \mathrm{mM}$ $\mathrm{Na}_{3} \mathrm{VO}_{4}$ ) containing protease inhibitor cocktail for $30 \mathrm{~min}$ on ice, and then centrifuged for $30 \mathrm{~min}$ at $30000 \mathrm{~g}$. Equal total proteins were electrophoresis by $12 \%$ SDS-PAGE gel, followed by transferred to PVDF membranes using a wet transblot system (Bio-Rad, Hercules, CA). The membranes were blocked for $1 \mathrm{~h}$ at room temperature with $5 \%$ nonfat dry milk and incubated overnight at $4{ }^{\circ} \mathrm{C}$ with antibodies against MT1-MMP, VEGF-C, VEGF-D and GAPDH (1:1000). After washing, membrane was incubated for $1 \mathrm{~h}$ with HRP-conjugated goat anti-rabbit secondary antibody diluted 1:5,000 in PBST. After further washing and processing using Super Signal West Pico chemiluminescent substrate (Pierce, USA), the membrane was exposed to Fujifilm LAS3000 Imager (Fuji, Japan). The band densities of the western blots were normalized and compared to the relevant GAPDH band density with Image J Analyst software (NIH).

\section{Enzyme-linked immunosorbent assay}

A549 cells were treated as previously described. Concentrations of MMP-9, MMP-2, VEGF in the cell culture supernatants were quantified using ELISA kits (R\&D Systems, USA). Each sample was repeated 5 times.

\section{Statistical analysis}

The experiments were carried out in triplicate and the data were compared to control group. Statistical analysis was performed by SPSS13.0, measurement data using paired t-test and ANOVA. A $P$ value of less than 0.05 was thought to indicate statistical significance.
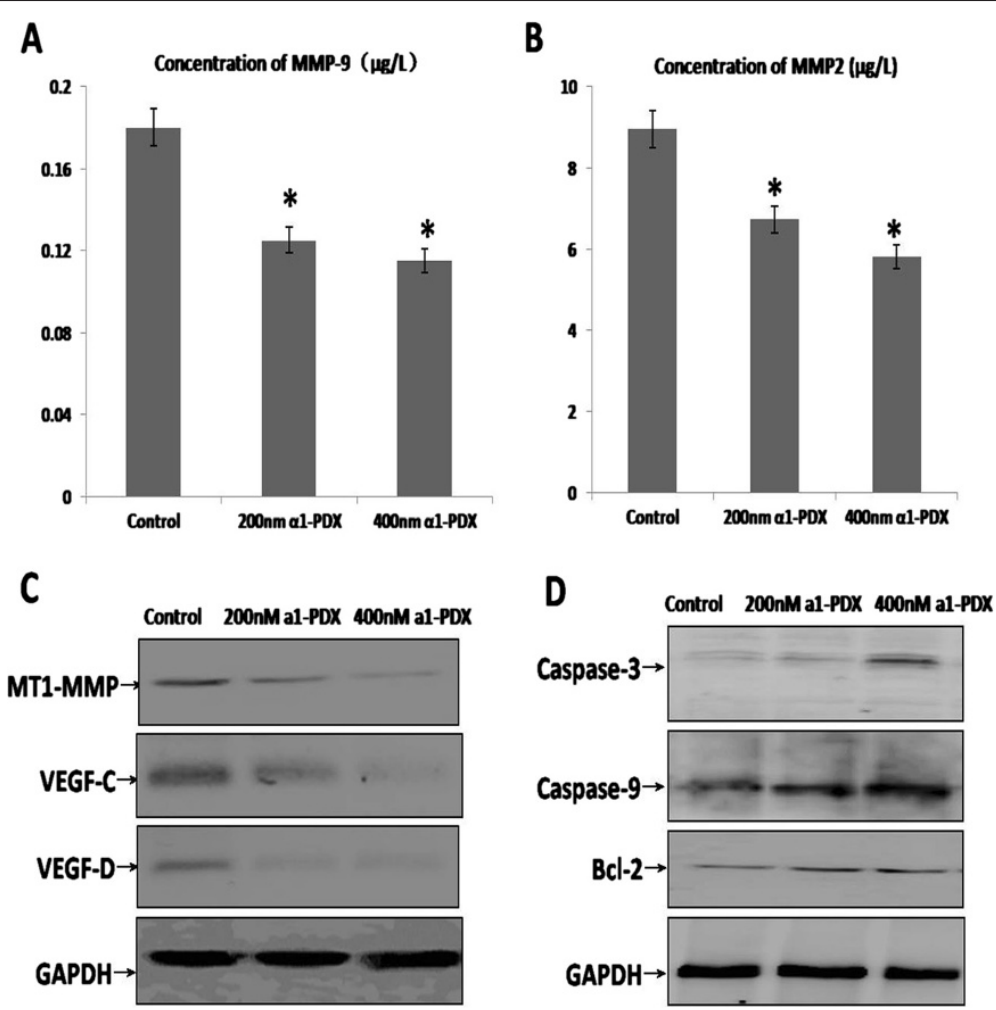

Figure 5 Effect of a1-PDX on the expression of migration and apoptosis proteins in A549 cells. MMP2 and MMP9 in SW480 cell culture medium were detected by ELISA assay (A and $\mathbf{B})$. The data represent the Mean \pm SE from three independent experiments. $\left({ }^{*} P<0.05\right.$ vs control ). The expression of cell migration and apoptosis proteins in A549 cells were detected with western blot (C and D). 


\section{Results}

Effects of a1-PDX on proliferation and colony formation abilities of A549 cell

A549 cell growth was inhibited upon treatment with a1PDX for over 48 hours (Figure 1A). Then, colony formation assay was performed to detect the clones of A549 cell. The result showed that the colony formation ability of A549 cell was decreased significantly compared to the control group (Figure 1B).

\section{Effects of a1-PDX on apoptosis of A549 cells}

To explore the mechanism of a1-PDX on A549 cell growth inhibition, we first used Hochest33342/PI double staining to detect the morphological change of apoptosis cells. The results showed that a1-PDX can induce apoptosis of A549 cells (Figure 2).

\section{Effects of a1-PDX on A549 cell migration and invasion}

To study whether the migration and invasion of A549 cells were regulated by a1-PDX, we then used wound healing and Transwell assays. Two experimental results showed that the migration and invasion capabilities of A549 cells were reduced evidently by a1-PDX compared to the control group (Figures 3 and 4).

To fully understand the molecular mechanism of A549 cells migration and apoptosis regulated by a1-PDX, we detected the expression of some proteins with Western Blot and ELISA assay (Figure 5). The concentrations of MMP2, MMP9 in cell culture medium reduced significantly compared to the control group (Figure 5A, B). The expression of MT1-MMP, VEGF-c and VEGF-d decreased significantly compared to the control group (Figure $5 \mathrm{C}$ ). However, the expression of Caspase-3, Caspase- 9 and Bcl-2 were increased evidently in a1-PDX treated groups (Figure 5D).

\section{Discussion}

Tumor metastasis is a complex multi-step process. Many proteins involve in the process of tumor metastasis. As we all know, the tumor extracellular matrix digestion is the most common prerequisite for tumor invasion and metastasis. Tumor cells secrete MMP family members (MMPs) could degrade all of the important extracellular matrix components [11,12]. Thus, the expression of matrix metalloproteinases could effectively reflect the ability of tumor cell invasion. It was proven that matrix metalloproteinase MMP2 and MMP9 degraded the basement membrane was a crucial step that promote tumor invasion and metastasis in many types of tumors [13].

In our current study, a1-PDX could not only inhibit the expression of cell migration proteins, but also increase the expression of cell apoptosis proteins, that induced cell apoptosis. MT1-MMP was Furin substrates, so MT1-MMP precursor was required to be cut by Furin before the maturation [4]. A1-PDX reduced the enzymic activity of Furin, thus reducing the maturation and activation of MT1-MMP. It was further suppressed the maturation of MMP2 and MMP9.

The enhanced expression of VEGF-C and VEGF-D and the lymphatic metastasis of tumor cells had been considered as a prognostic indicator of several types of cancers $[14,15]$. Their precursors needed to be cut by Furin before maturation and activation [16]. Therefore, we also have examined the expression of VEGF-C and VEGF-D protein in A549 cells which were treated by a1PDX. The results show that the expressions of VEGF-C and VEGF-D protein are significantly reduced.

\section{Conclusions}

Taken together, we conclude that Furin inhibitor suppressed A549 cell migration through down-regulating the activity of Furin. The subsequent regulation plays a critical role in A1-PDX-induced migration inhibition and apoptosis in A549 cells. Furin inhibitor may, therefore, have a potential use as a target in the treatment of lung cancer.

\section{Abbreviations}

NSCLC: Non-small cell lung cancer; VEGF: Vascular endothelial growth factor; MMPs: Matrix metalloproteinases.

\section{Competing interests}

The authors declare that they have no competing interests.

\section{Authors' contributions}

YCM, STX designed research; YCM, WJF and SMR performed the experiments and data analysis; LG and ZYB contributed new reagents and analytic tools; YCM, STX wrote the paper. All authors read and approved the final manuscript.

\section{Acknowledgements}

This work was supported by the Natural Science Foundation of Luo He Medical College, Henan province, P.R.C. (2013-DF-001; 2013-S-LMC03).

\section{Disclosure of financial support}

This work was supported by the Natural Science Foundation of Luo He Medical College, Henan province, P.R.C. (2013-DF-001).

Received: 10 December 2013 Accepted: 11 March 2014 Published: 22 May 2014

\section{References}

1. Weir HK, Thun MJ, Hankey BF: Annual report to the nation on the status of cancer, 1975-2000, featuring the uses of surveillance data for cancer prevention and control. J Natl Cancer Inst 2003, 95(17):1276-1299.

2. Sakashita S, Sakashita M, Sound Tsao M: Genes and pathology of non-small cell lung carcinoma. Semin Oncol 2014, 41(1):28-39.

3. Thomas $\mathrm{G}$ : Furin at the cutting edge: from protein traffic to embryogenesis and disease. Nat Rev Mol Cell Biol 2002, 3(10):753-766.

4. Basak A, Chen A, Scamuffa N, Mohottalage D, Basak S, Khatib AM: Blockade of furin activity and furin-induced tumor cells malignant phenotypes by the chemically synthesized human furin prodomain. Curr Med Chem 2010, 17(21):2214-2221.

5. Couture F, D'Anjou F, Desjardins R, Boudreau F, Day R: Role of proprotein convertases in prostate cancer progression. Neoplasia 2012, 14(11):1032-1042.

6. Lalou C, Basak A, Mishra P, Mohanta BC, Banik R, Dinda B, Khatib AM: Inhibition of tumor cells proliferation and migration by the flavonoid furin inhibitor isolated from Oroxylum indicum. Curr Med Chem 2013, 20(4):583-591.

7. Cavallar U, Christofori G: Multitasking in tumor progression: signaling function of cell adhension molecules. Ann N YAcad Sci 2004, 10(14):58-66. 
8. Bassi DE, Mahloogi $\mathrm{H}$, Al-Saleem L: Elevated Furin expression in aggressive human head and neck tumors and tumor cell lines. Mol Carcinog 2001, 31(4):224-232.

9. Scamuffa N, Sfaxi F, Ma J, Lalou C, Seidah N, Calvo F, Khatib AM: Prodomain of the proprotein convertase subtilisin/kexin Furin (ppFurin) protects from tumor progression and metastasis. Carcinogenesis 2014, 35(3):528-536.

10. Mbikay M, Sirois F, Yao J: Comparative analysis of expression of the proprotein convertases furin, PACE4, PCl and PC2 inhuman lung tumours. Br J Cancer 1997, 75(10):1509-1514.

11. Gao J, Ding F, Liu Q, Yao Y: Knockdown of MACC1 expression suppressed hepatocellular carcinoma cell migration and invasion and inhibited expression of MMP2 and MMP9. Mol Cell Biochem 2012, 12:1545-1557.

12. Hotary KB, Allen ED, Brooks PC, Datta NS, Long MW, Weiss SJ: Membrane type I matrix metalloproteinase usurps tumor growth control imposed by the three-dimensional extracellular matrix. Cell 2003, 114(1):33-45.

13. Rozanov DV, Golubkov VS, Strongin AY: Membrane type-1 matrix metalloproteinase (MT1-MMP) protects malignant cells from tumoricidal activity of re-engineered anthrax lethal toxin. Int J Biochem Cell Biol 2005, 37(1):142-154.

14. Stacker SA, Caesar C, Baldwin ME: VEGF-D promotes the metastatic spread of tumor cells via the lymphatics. Nat Med 2001, 7:186-191.

15. Nagy JA, Vasile E, Feng D: Vascular permeability factor/vascular endothelial growth factor induces lymphangiogenesis as well as angiogenesis. J Exp Med 2002, 196:1497-1506.

16. Voura EB, English JL, Yu HY, Ho AT, Subarsky P, Hill RP, Hojilla CV, Khokha R: Proteolysis during tumor cell extravasation in vitro: metalloproteinase involvement across tumor cell types. PLoS One 2013, 8(10):e78413.

doi:10.1186/1475-2867-14-43

Cite this article as: Ma et al.: Effect of Furin inhibitor on lung adenocarcinoma cell growth and metastasis. Cancer Cell International 2014 14:43.

\section{Submit your next manuscript to BioMed Central and take full advantage of:}

- Convenient online submission

- Thorough peer review

- No space constraints or color figure charges

- Immediate publication on acceptance

- Inclusion in PubMed, CAS, Scopus and Google Scholar

- Research which is freely available for redistribution 